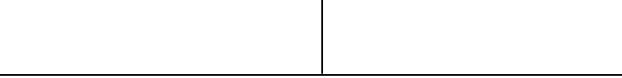

Rev. Latinoam. Psicopat. Fund., São Paulo, v. 11, n. 4, p. 616-625, dezembro 2008

\title{
Quando a adolescência não depende da puberdade*
}

Tiago Corbisier Matheus

Este artigo pretende rever a concepção de adolescência como crise necessária, universalmente deflagrada pela puberdade, tal como se difundiu na psicanálise a partir da perspectiva desenvolvimentista. Fazendo uso da perspectiva historiográfica e da retomada da obra freudiana, é possível propor a distinção daquilo que diz respeito ao personagem adolescente, cronológica e sociologicamente determinado, da questão adolescente, que diz respeito a cada sujeito, com quem a psicanálise está comprometida.

Palavras-chave: Adolescência, puberdade, indivíduo, crise

* O argumento deste artigo encontra-se desenvolvido no trabalho Adolescência: história e política do conceito na psicanálise.

A apresentação oral deste artigo foi feita no XVII Congresso da FLAPAG, VI Congresso do NESME, ocorrido em 31 de maio a 3 de junho 2007, em Santos, SP. 
Adolescência é um termo que, em sua versão latina (adulescentia), já era utilizado desde os idos tempos do Império Romano, nos séculos I e II, a fim de descrever e delimitar um período específico na vida dos cidadãos, conforme previa a rígida hierarquia patriarcal. A organização social da época organizava-se em torno dessa hierarquia, não havendo, no entanto, a separação entre as dimensões do público e do privado, como viria a ocorrer posteriormente, na modernidade. Naquele momento, moral, sexualidade e política articulavam-se num todo único, em que homem e natureza estavam mutuamente implicados, como elementos pertencentes à “ordem natural” do universo, conforme a cultura romana da época. A adulesentia, por sua vez, era caracterizada como um momento anterior à participação na vida comunitária, que ocorria somente a partir da iuventus. A submissão à rígida hierarquia patriarcal própria da adulesentia era, então, esperada e até aceita, em decorrência não somente das perspectivas previstas na etapa seguinte, mas da própria razão natural da vida, que regia cada um de seus elementos (Fraschetti, 1996).

Na Idade Média européia, também há registros do uso do termo adulesentia, mas seu entendimento não era consensual e se restringia à descrição erudita das diferentes fases de vida. No senso comum, eram as funções sociais que distinguiam os lugares designados para cada faixa etária. Essa divergência entre o vivido e o discurso erudito anunciava a cisão que veio se consolidar, na cultura ocidental, entre o homem e a natureza; era o prenúncio da fragmentação dos saberes que buscavam compreender o ser humano.

No que diz respeito à função social da juventude medieval, havia uma ambivalência entre o papel transgressor e o compromisso com a defesa da moral e da ordem da vida cotidiana. Cabia aos jovens de cada comunidade a organização das festividades, sendo aceita sua conduta transgressiva, pois, ao disporem do espaço público, também se responsabilizavam por zelar pela conduta moral de cada membro da comunidade frente aos demais. Nesse sentido, os jovens estavam longe de representar uma ameaça e cumpriam com funções que deles era esperada (Schindler, 1996).

É na Idade Moderna que a noção de adolescência como momento de turbulência e crise surge, consolidando-se como tal na contemporaneidade. Herdeira de um pensamento antropocêntrico, que localiza o homem no centro do universo, a cultura européia dos séculos XVII e XVIII anuncia o desafio da formação de um novo homem, aquele que seria capaz de realizar o ideá-

Rev. Latinoam. Psicopat. Fund., São Paulo, v. 11, n. 4, p. 616-625, dezembro 2008 
rio iluminista, pautado pela noção de racionalidade e de autodeterminação. A noção de indivíduo, portadora primordial desse ideário, é então posta no vértice da organização social moderna, não mais regida por uma ordem transcendental, como ocorria na época medieval, mas por leis reconhecidamente humanas, que se justificavam por sua fundamentação racional e amplitude universal.

Em tal contexto, parte da tensão que até então percorria e sustentava o tecido social é deslocada para o indivíduo em sua singularidade, de modo que cada um passa a se responsabilizar por suas próprias escolhas, caminhos e infortúnios. Se até então o destino dos servos e dos nobres já estava definido de antemão, na modernidade surge uma inusitada mobilidade social representada na figura do indivíduo livre, pretensamente capaz de construir sua realidade e definir sua fortuna. Palco de conflitos e turbulências, o indivíduo é então dotado de uma interioridade, configurando assim o chamado processo de subjetivação do homem moderno, bem como a dicotomia entre os espaços público e privado característica da modernidade (Figueiredo, 1999).

É a partir desse contexto anunciado que surge a configuração específica de adolescência que veio a se difundir na contemporaneidade. Desponta como corolário da noção de indivíduo, a crise da adolescência, que acaba funcionando como condição para sua efetivação: circunscreve a um momento específico da vida, com um fim previamente estabelecido, turbulências inevitáveis que cada sujeito é convocado a experimentar, a fim de conquistar a condição de indivíduo, seguindo as diretrizes do ideário da modernidade. A crise é, então, fruto do exercício da interioridade de cada um, em função das tensões e conflitos que a configuram como tal. É o preço a ser pago pela pretensa condição de independência frente às amarras da organização social; é expressão do desamparo que sua condição (imaginária) de autonomia exige, servindo, ao sujeito, como provação anônima para alcançar o estatuto de indivíduo. Essa experiência subjetiva, ao ser circunscrita à interioridade de cada indivíduo, resulta, aliás, no velamento do jogo de forças sociais do qual é resultante, servindo de apoio às estruturas sociais vigentes.

No entanto, quando se considera a perspectiva relacional e personalista que segue presente nas heterogêneas experiências cotidianas da sociedade brasileira (ou sociedades brasileiras, para ser mais preciso), marcada pelo modelo de hierarquia familiar patriarcal, o trajeto adolescente ganha uma nuança particular. Numa sociedade de tradição relacional, a hierarquia percorre os vários lugares na rede de influências e se ramifica nos diferentes espaços sociais, exigindo do sujeito adolescente a construção de um sinuoso caminho, de modo a poder compartilhar dos códigos e prescrições específicos de cada contexto institucional. A almejada inclusão na cena do mundo adulto prevê, neste universo, provações e alianças - silenciosas ou anunciadas, momentâneas ou ritualizadas - 
que vêm instaurar o incerto jogo de poder característico de uma realidade marcada pela informalidade. Nessa perspectiva, o trajeto adolescente depende não somente de uma intimização própria do processo de subjetivação, mas também da construção de laços entre pares ou com representantes das hierarquias institucionais, de acordo com as vicissitudes específicas de cada contexto imediato e particular. A crise, aqui, se dá em função do possível e provável impacto que é, para cada um, se defrontar com a desigualdade de posições que tal hierarquia estabelece, assim como com o peso do exercício do poder, em sua modalidade informal e personalista.

Constata-se, a partir daí, que a crise da adolescência não é a mesma para os vários sujeitos implicados nas distintas realidades sociais da atualidade. Se ela é uma conseqüência inevitável do processo de subjetivação característico da contemporaneidade, de acordo com o ideário do indivíduo que lhes serve de fundamento, não deixa de sofrer variações de acordo com a tradição cultural de cada organização social em particular.

Uma das teses que vem sendo defendida entre pesquisadores da adolescência a considera como decorrência da fragilidade da função exercida pelos ritos de passagem na atualidade (ver Dolto, 2004, p. 20 e 34; Melman, 1999, p. 40; Alberti, 1999, p. 28). O argumento anuncia a adolescência como trabalho psíquico decorrente da falta de dispositivos societários socialmente compartilhados, justificando assim a crise ou pane do sujeito: cada um é convocado a produzir singularmente dispositivos que lhe permitam a construção de um sentido para a estranheza com a qual se defrontam num momento de passagem, uma vez que o campo simbólico que encontram à disposição não mais prescreve de modo claro nem quando e nem como alguém deixa de ser criança e se insere no mundo adulto.

No entanto, paradoxalmente, a adolescência descrita como crise inevitável, decorrência da ausência de rituais, se torna ela própria um ritual, vivido na singularidade de cada um, como experiência necessária à pretensa inserção no mundo adulto. Trata-se de um dispositivo próprio da contemporaneidade, no qual é preciso viver uma provação para se conquistar a condição de ser adulto, aquele que se supõe dispor dos privilégios de participar de uma rede de trocas, sendo respeitado em seus direitos de legítimo cidadão.

A difusão no senso comum da adolescência como crise necessária, turbulência inevitável, mas passageira, a ser suportada pelos vários personagens que a experimentam - na própria pele ou na de seus interlocutores -, serve como reafirmação desse ritual anônimo. A circulação de tal significante serve como ponto de identificação para o sujeito que, errante, não encontra referências simbólicas compartilhadas a respeito de si, a não ser a imagem de um adolescente em crise. Portanto, se por um lado há um vácuo simbólico que justifica a crise adolescen- 
te, por outro, esse significante passa a ser a própria referência compartilhada, anonimamente, pelos sujeitos que pleiteiam pertinência e reconhecimento no corpo social.

No meio psicanalítico, a pesquisa sobre o tema da adolescência manifesta a tensão que subsiste entre a psicanálise e a perspectiva histórica, tensão esta raramente apontada e debatida entre psicanalistas, sobretudo entre aqueles que discutem este tema de pesquisa. Se vários autores têm buscado estabelecer diálogo com a historiografia, inscrevendo a adolescência nos processos históricos deflagrados a partir da modernidade, como sugere o tão citado trabalho de Áries (1975), não deixam, porém, de expressar as marcas que carregam, muitos deles, de uma concepção de adolescência desenvolvimentista, que tende a estabelecer uma cronologia para a adolescência, pondo em risco a concepção radical de sexualidade e de sujeito anunciados por Freud. Ocorre que a perspectiva histórica enfatiza o caráter humano e conjuntural que sustenta concepções tais como esta, a crise da adolescência, cerceando a pretensão de atribuir-lhe um estatuto universal e trans-histórico, tal como foi proposto pela ego psychology, que argumentou em favor da naturalização da referida crise.

Baseando-se no próprio texto freudiano e seguindo uma perspectiva desenvolvimentista, muitos autores herdeiros dessa tradição descreveram a adolescência como uma decorrência psíquica de processos orgânicos característicos da puberdade, estabelecendo, direta ou indiretamente, uma seqüência linear entre esses dois eventos. Ainda que a puberdade possa ser compreendida apenas como evento disparador da adolescência, tal formulação tende a estabelecer uma relação de subordinação entre as ocorrências (orgânica e psicológica), fazendo supor que na adolescência a sexualidade voltaria a se apoiar na autoconservação, a partir das determinações genéticas previamente estabelecidas. Esse argumento retoma o único texto em que Freud elegeu a puberdade como tema, no terceiro dos "Três ensaios sobre a teoria sexualidade". Ali, de fato, o fundador da psicanálise assinala que o incremento da pulsão sexual ocorrido na puberdade demanda a reordenação das pulsões parciais sob o primado da genitalidade, culminando na escolha objetal definitiva. Se na tradução de tal passagem a pulsão for tomada como instinto e a puberdade for definida como fenômeno orgânico, tal como atualmente comumente se supõe, a concepção precedente se mostraria inevitável e seriam os instintos pubertários, fisiologicamente determinados, que viriam a deflagrar os processos subjetivos hoje associados à adolescência.

Porém, há muito que se alerta para os riscos de se tomar a pulsão como instinto, assim como é preciso considerar que o uso que Freud fazia do termo puberdade não se restringia especificamente às transformações fisiológicas. Ele pouco falava em adolescência, termo incomum na época, mas se referia constantemente à puberdade, como segundo momento da sexualidade humana. Preo- 
cupado com a etiologia das neuroses, Freud se referiu à puberdade durante toda sua obra, a fim de discutir esse momento segundo, durante o qual a estrutura do aparelho psíquico adquire sua configuração definitiva. É quando as marcas infantis, após um período de amortecimento (latência), próprio à condição humana, seriam resgatadas e ressignificadas, conforme as possibilidades e recursos disponíveis para cada sujeito. Tal processo se dá em função da inversão temporal que o mecanismo de posterioridade estabelece entre as marcas infantis e esse segundo momento, que retroage sobre os primeiros, atribuindo-lhes um sentido outro.

Falar em incremento pulsional, portanto, não sugere que esse segundo momento da sexualidade humana seja necessariamente deflagrado por fatores geneticamente determinados. Fazer tal correlação é resultado de uma questionável leitura de Freud, que destaca apenas os pontos mais evidentes do texto de 1905, deixando em segundo plano o caráter plástico e enigmático da sexualidade, bem como a produção teórica do autor que foi produzida posteriormente, quando conceitos tais como identificação e pulsão de morte restringem qualquer perspectiva finalista para a experiência humana. Se no texto sobre a puberdade Freud havia apontado a síntese das pulsões parciais, posteriormente irá sublinhar o caráter incompleto desse processo e o mal-estar dele resultante.

Há que se considerar que a própria puberdade está sujeita à intervenção do universo simbólico na qual se inscreve, ainda que não esteja a ele subordinado, podendo ser antecipada ou postergada conforme o contexto no qual cada indivíduo se insere e a história de vida que o singulariza (ver Graber et al., 1995). Como se sabe, as transformações pubertárias se estendem por vários anos (em torno de três ou quatro) e não parece sem motivo que vários autores próximos à área médica prefiram descrevê-las como ocorrências concomitantes a condutas usualmente associadas à adolescência (como os ensaios de experiências amorosas e os confrontos com figuras parentais) - (ver Saito; Silva, 2001). ${ }^{1}$

Entende-se que a puberdade pode por vezes funcionar como elemento disparador do segundo momento da sexualidade, mas não como condição necessária. É, sobretudo, a partir do olhar do outro, ou da imagem especular que este anuncia, que surge, para o sujeito, um corpo estranho, um componente novo em seu psiquismo que não encontra registro entre os recursos simbólicos disponíveis. Esse olhar e essa imagem não estão presos à concretude da realidade, uma

1. Os dados sobre a ocorrência da puberdade na realidade brasileira indicam as idades médias: de 9,7 anos aos 13,4 para meninas e de 10,9 a 15,6 para meninos. Outeiral observa recentemente uma conduta adolescente em indivíduos não púberes, com idades em torno de oito a dez anos (2001, p. 23).

Rev. Latinoam. Psicopat. Fund., São Paulo, v. 11, n. 4, p. 616-625, dezembro 2008 
vez que esta é sustentada pelo campo simbólico que a fundamenta e acompanha. Da realidade, busca-se ao menos um grão que sirva de suporte para o real a ser confrontado, disparado pela estranheza do olhar do outro. São as imagens de um corpo transformado, produzidas em meio a este ou a tantos outros, que instigam o retorno do recalcado, inaugurando o segundo momento da sexualidade. É por esse motivo que o momento adolescente independe imediatamente da puberdade, pois está atrelado aos sentidos que aquele corpo conquista nos laços nos quais se inscreve.

O caso da criança tomada como objeto sexual antes dos sinais pubertários é uma situação em que essa inversão fica explicitada e é capaz de justificar a antecipação do segundo momento da sexualidade, produzindo seus efeitos para quem a vive.

A questão da puberdade assinala uma das polaridades do pensamento de Freud, que se manteve presente em toda a obra, variando seu peso e ênfase de acordo com a conjuntura teórica e política do momento. Se, por um lado, as transformações pubertárias são determinantes que não podem ser desconsiderados na obra de Freud, por outro, estes não permitem a sustentação de uma relação causal e linear entre a maturação orgânica e os determinantes da ordem do campo simbólico (que ganhariam importância após 1905) sustentados pela complexidade das redes de identificações e escolhas objetais, pautadas como são por ambivalências e contradições. Se o próprio Freud já percebia desde o início que o ponto mais problemático de sua obra recaía sobre a teoria das pulsões, é porque o efeito do dito "orgânico" sobre a subjetividade segue emblemático, ainda que muitas vezes a menção a esse fator seja vista como garantia de veracidade do saber produzido.

Entende-se que o segundo momento da sexualidade humana ocorre após o período de amortecimento (latência), no qual uma experiência sexual, narcísica e enigmática, surpreende o sujeito, sendo então convocado a resgatar e ressignificar suas lembranças precedentes, marcando (definitivamente) sua constituição psíquica. É o efeito retardado do segundo momento que incide sobre as marcas anteriores que lhes confere um sentido, deixando um resto carente de sentido o traumático - a partir do qual o psiquismo se organiza. Esse resto diz respeito tanto ao sexual diretamente considerado, quanto às questões narcísicas que entram em cena em função dos conflitos de autoridade e poder. É o momento de confronto com as fissuras do tecido social, inicialmente amortecido pela instituição familiar (Rosa, 2002, p. 230), no hiato entre a autoridade parental e as que a substituem no meio social. É o momento em que a busca de autonomia frente às referências familiares lança o sujeito num estado de desamparo e movimento, que o torna disponível para sustentar diferentes imagens que lhe são atribuídas na cena social, bem como fazer uso, em seu gesto e discurso, de sua capacidade de enun- 
ciação. Trata-se de um lugar estrangeiro, marcado tanto por um pedido de pertinência, quanto pela inquietação e irreverência que seu desprendimento permite, no sabor e na dor que o acompanham (ver Matheus, 2007).

Foi decisivo para a psicanálise poder discriminar o que diz respeito ao infantil que acompanha cada sujeito daquilo que concerne à infância, pautada pela história de vida de cada um, que busca incessantemente reescrevê-la. O infantil diz respeito ao passado que se faz presente, numa atualização que subverte a noção de tempo que fala da seqüência cronológica da infância. A escuta do analista, por sua vez, almeja oferecer lugar ao infantil que restou da infância, fazendo eco ao descompasso temporal que acompanha cada sujeito em seus movimentos circulares.

No caso da adolescência, há que se descolar o fenômeno social e seus personagens da questão adolescente, tal como esta se anuncia para o sujeito (que não coincide com o indivíduo). A questão adolescente diz respeito aos impasses do sujeito que, no anseio de se desprender de suas referências familiares, confronta-se com os enigmas da sexualidade e com as incongruências da organização social da qual participa. O personagem adolescente, comumente associado a uma faixa etária específica (os teens, como a mídia tem nomeado), pode ou não se defrontar com tais questões, conforme o permitam sua estrutura psíquica e os recursos que lhe são oferecidos pelo contexto em que se insere. Se é possível a um sujeito abandonar o personagem adolescente, quando alcança outras posições no jogo de forças sociais, o mesmo não ocorre com a questão adolescente. Tal como o resto infantil, que insiste em se fazer presente, nas infinitas repetições do recalcado, cada sujeito nunca chega a se desprender de todo de suas figuras de autoridade, assim como não lhe é possível alcançar um sentido pleno para a estranheza que o invade pelos poros ou pelo dissonante olhar alheio.

A discriminação entre sujeito e fenômeno adolescente permite à escuta analítica resgatar a radicalidade de seu exercício, comprometida como está com o sujeito e seu desejo, tanto na clínica em sentido estrito, quanto na clínica ampliada, que em função do destaque dos fenômenos juvenis na atualidade tem sido um foco de demanda para a psicanálise, naquilo que esta é capaz de dizer sobre o sujeito que se enuncia em cada sintoma social. A discriminação entre sujeito e fenômeno adolescente, tal como foi indicado, permite à psicanálise evitar a naturalização da questão adolescente e considerar sua inscrição histórica, o que certamente limita as pretensões que outrora foram anunciadas para este saber. Por outro lado, tal distinção permite lembrar qual o objeto de investigação da psicanálise e qual sua contribuição específica sobre o tema da adolescência, estabelecendo bases para um campo de diálogo entre as diferentes áreas das ciências humanas, cada qual com sua especificidade, na tensão que aí subsiste, inevitavelmente.

Rev. Latinoam. Psicopat. Fund., São Paulo, v. 11, n. 4, p. 616-625, dezembro 2008 


\section{Referências}

Alberti, S. Esse sujeito adolescente. Rio de Janeiro: Rios Ambiciosos, 1999.

Arıès, P. L'enfant et la vie familiale sous l'Ancien Régime. Vienne: Seuil, 1975.

Dolto, F. A causa dos adolescentes. Trad. de O. dos Reis. Aparecida: Idéias \& Letras, 2004.

Figueiredo, L. C. A invenção do psicológico: quatro séculos de subjetivação (15001900). 4. ed. São Paulo: Escuta/Educ, 1999.

Fraschetti, A. O mundo romano. In: Levi, G.; Schmitt, J.-C. (Orgs.). História dos jovens. Trad. de C. Marcondes, N. Moulin, P. Neves. São Paulo: Companhia das Letras, 1996. v. 1, p. 59-95.

Freud, S. (1905). Tres ensayos de teoría sexual. In: Obras Completas. Trad. de J. L. Etcheverry. Buenos Aires: Amorrortu, 1993. v. 7.

Graber, J. A.; Gunn, J. B.; Warren, M. P. The Antecedents of Menarcheal Age: Heredity, Family Environment, and Stressful Life Events. Child Development, v. 66, n. 2, p. 346359, Apr. 1995.

Matheus, T. C. Adolescência: história e política do conceito na psicanálise. São Paulo: Casa do Psicólogo, 2007.

Melman, C. Os adolescentes estão sempre confrontados ao Minotauro. In: Associação Psicanalítica de Porto Alegre. Adolescência entre o passado e o futuro. Porto Alegre: Artes e Ofícios, 1999. p. 29-44.

Outeiral, J. Adolescência: modernidade e pós-modernidade. In: WeinBerg, C. Geração delivery: adolescer no mundo atual. São Paulo: Sá, 2001. p. 115-125.

Rosa, M. D. Adolescência: da cena familiar à cena social. Psicologia USP, São Paulo, v. 13, n. 2, p. 227-242, 2002.

SAito, M. I.; SiLva, L. E. Adolescência: prevenção e risco. São Paulo: Atheneu, 2001.

SCHINDLER, N. Os tutores da desordem: rituais da cultura juvenil nos primórdios da era moderna. In: Levi, G.; Schмiтt, J.-C. (Org.). História dos jovens. Trad. de C. Marcondes, N. Moulin, P. Neves. São Paulo: Companhia das Letras, 1996. v. 1, p. 265-324.

\section{Resumos}

(Cuando la adolescencia no depende de la pubertad)

Este artículo tiene el objetivo de cuestionar la concepción de adolescencia en cuanto crisis necesaria, universalmente desencadenada por la pubertad, tal y como se 
ha difundido en psicoanálisis desde la perspectiva desarrollista. Utilizando la perspectiva historiográfica y retomando la obra de Freud, ha sido posible proponer la distinción entre lo que atañe al personaje adolescente, cronológica y sociológicamente determinado, y la cuestión adolescente, que tiene que ver con cada sujeto, con quien el psicoanálisis está comprometido.

Palabras claves: Adolescencia, pubertad, individuo, crisis

(Quand l'adolescence ne dépend pas de la puberté)

Cet article met en question la conception d'adolescence en tant que crise nécessaire, universellement déflagrée par la puberté, tel qu'elle s'est répandue dans la psychanalyse à partir de la perspective de la psychologie du moi. C'est à partir de la perspective de l'historiographie et en reprenant l'oeuvre de Freud, qu'il a été possible d'établir une distinction entre ce qui concerne le personnage adolescent, chronologique et sociologiquement déterminé, et la question adolescente, qui concerne chaque sujet avec lequel la psychanalyse s'engage.

Mots clés: Adolescence, puberté, individu, crise

(When adolescence does not depend on puberty)

This paper questions the conception of adolescence as a necessary crisis universally triggered by puberty, as has been held by psychoanalysis from the developmental perspective. Based on history and on Freud's works, a distinction cam be made between the adolescent as chronologically and sociologically determined, and the impasse of adolescence, which is based on the subject of the unconscious, the sole concern of psychoanalysis.

Key words: adolescence, puberty, individual, crisis

Versão inicial recebida em julho de 2007

Versão aprovada para publicação em outubro de 2008

\section{Tiago Corbisier Matheus}

Psicanalista, membro do Departamento de Psicanálise do Instituto Sedes Sapientiae (são Paulo, SP, Brasil); doutor em Psicologia Social pela Pontifícia Universidade Católica de São Paulo - PUC-SP (São Paulo, SP, Brasil); também exerce atividade docente na Fundação Getúlio Vargas - FGV (São Paulo, SP, Brasil) e de supervisão na Universidade Paulista - UNIP (São Paulo, SP, Brasil).

Rua Fradique Coutinho, 1640/42

05416-001 São Paulo, SP, Brasil

e-mail: tmatheus@uol.com.br

Rev. Latinoam. Psicopat. Fund., São Paulo, v. 11, n. 4, p. 616-625, dezembro 2008 